\title{
Factors Associated with Adverse Events during Tracheal Intubation in the NICU
}

\author{
Elizabeth E. Foglia ${ }^{a} \quad$ Anne Ades $^{a}$ Natalie Napolitano ${ }^{b} \quad$ Jessica Leffelman ${ }^{c}$ \\ Vinay Nadkarni ${ }^{c, d}$ Akira Nishisaki ${ }^{c, d}$ \\ ${ }^{a}$ Division of Neonatology, ${ }^{b}$ Department of Nursing and Respiratory Care, ${ }^{c}$ Center for Simulation, Advanced \\ Education and Innovation, and d Department of Anesthesiology and Critical Care Medicine, The Children's \\ Hospital of Philadelphia, Philadelphia, Pa., USA
}

\section{Key Words}

Adverse events · Intubation - Newborn resuscitation .

Intensive care Outcomes

\begin{abstract}
Background: The incidence of adverse tracheal intubationassociated events (TIAEs) and associated patient, practice, and intubator characteristics in the neonatal intensive care unit (NICU) setting are unknown. Objectives: To determine the incidence of adverse TIAEs and to identify factors associated with TIAEs in the NICU. Methods: Single-site prospective observational cohort study of infants who were intubated in a level 4 referral NICU between September 1, 2011 and November 30, 2013. A standardized pediatric airway registry was implemented to document patient, practice, and intubator characteristics and outcomes of intubation encounters. The primary outcome was adverse TIAEs. $R \boldsymbol{e}$ sults: Adverse TIAEs occurred in 153 of 701 (22\%) tracheal intubation encounters. Factors that were independently associated with lower incidence of TIAEs in logistic regression included attending physician (vs. resident; odds ratio (OR) $0.4,95 \% \mathrm{Cl}: 0.16,0.98)$ and use of paralytic medication (OR $0.45,95 \% \mathrm{Cl}: 0.25,0.81$ ). Severe oxygen desaturations ( $\geq 20 \%$ decrease in oxygen saturation) occurred in $51.1 \%$ of encounters and were more common in tracheal intubations performed by residents (62.8\%), compared to fellows (43.2\%) or
\end{abstract}

attendings (47.5\%; $p=0.008)$. Conclusions: Adverse TIAEs and severe oxygen desaturation events are common in the NICU setting. Modifiable risk factors associated with TIAEs identified include intubator training level and use of paralytic medications.

(c) 2015 S. Karger AG, Basel

\section{Introduction}

Tracheal intubation (TI) is a life-saving but technically challenging procedure, which carries a meaningful risk of morbidity and mortality for critically ill infants and children [1-4]. Medical training level is associated with both success of TI and the incidence of adverse tracheal intubation-associated events (TIAEs) in the pediatric intensive care unit (PICU) $[1,4]$. In a combined study of neonatal and pediatric patients, TI attempts by inexperienced operators were more likely to result in oxygen desaturation and bradycardia episodes [5].

Little is known regarding the incidence and characteristics of adverse TIAEs in the neonatal intensive care unit (NICU). The objectives of this study were to characterize the incidence of adverse TIAEs and severe oxygen desaturation during $\mathrm{TI}$ and to determine the association of patient, practice, and intubator characteristics with adverse TIAEs in a large academic NICU. We hypothesized that

\section{KARGER 125}

(c) 2015 S. Karger AG, Base

$1661-7800 / 15 / 1081-0023 \$ 39.50 / 0$ 
intubator training level would be associated with occurrence of adverse TIAEs and severe desaturation events during TI, and that modifiable factors associated with TIAEs could be identified.

\section{Methods}

\section{Setting}

This was a prospective observational cohort study at the Children's Hospital of Philadelphia NICU, an 85-bed, level 4, referral NICU.

\section{Patient Selection}

All infants who underwent TIs with direct laryngoscopy between September 1, 2011 and November 30, 2013 in the NICU were identified for potential inclusion. Neonatal TIs performed outside the NICU were excluded. Intubations in the hospital's small referral delivery unit were excluded, as this delivery unit has only 300-400 specialized deliveries a year and has a separate staffing model. This study was performed within a convenience sample derived during the study period.

\section{Data Collection and Definitions}

A previously developed TI data collection tool, the National Emergency Airway Registry for Children (NEAR4KIDS), was used in the NICU [6]. Greater than 95\% compliance with data capture and accuracy were established. A respiratory therapist and intubator completed the data collection form after every intubation. A research assistant checked all data forms for completeness, interviewed participating clinicians for missing data when needed, and entered deidentified data into a secure web-based database.

Briefly, operational definitions are as follows 'Course' was defined as one method to intubate (i.e. oral or nasal) and one set of medications. We only included intubation encounters with one course in this analysis; many attempts could occur within this course. First-attempt success was defined as successful intubation on the first attempt. Overall success was defined as successful intubation by the initial intubator.

Patient demographics were abstracted from the medical record. Weight was recorded on the day of TI, not birth weight. A 'history of difficult airway' was reported based on any known prior history of difficulty managing the patient's airway. Intubator background and training level were recorded for every attempt; training level of the initial intubator was used in analysis. Medications were used according to the clinical team's preference and were classified as 'sedative/narcotic' (including opiates, benzodiazepines, and barbiturates) or 'paralytic' (including depolarizing or nondepolarizing neuromuscular blockade).

\section{Adverse Events}

Adverse events were classified into two categories: severe TIAEs and nonsevere TIAEs. Severe TIAEs included cardiac arrest, esophageal intubation with delayed recognition, emesis with witnessed aspiration, hypotension requiring intervention (fluid and/or vasopressors), laryngospasm, malignant hyperthermia, pneumothorax/pneumomediastinum, or direct airway injury. Cardiac arrest was defined as loss of perfusion or severe bradycardia requiring chest compressions for $\geq 1 \mathrm{~min}$.
Nonsevere TIAEs included mainstem bronchial intubation, esophageal intubation with immediate recognition, emesis without aspiration, hypertension requiring therapy, epistaxis, lip trauma, gum or oral trauma, medication error, dysrhythmia, and pain and/or agitation requiring additional medication and causing delay in intubation. Mainstem bronchial intubation was considered only when it was confirmed on chest radiograph or recognized after the clinical team secured the tracheal tube. Dysrhythmia included bradycardia requiring chest compressions for $<1$ min or arrhythmia requiring treatment.

The highest pulse oximetry saturation $\left(\mathrm{SpO}_{2}\right)$ measured prior to intubation (i.e. during preoxygenation) and the lowest measured $\mathrm{SpO}_{2}$ during the intubation encounter were recorded. Oxygen desaturation was calculated as the difference between these values. The same method was used for infants with cyanotic heart disease, as the relative difference between initial $\mathrm{SpO}_{2}$ and lowest $\mathrm{SpO}_{2}$ was used for analysis. If either the initial or lowest saturation was not reliably measured (i.e. from a poor waveform), oxygen saturation data were not included in analysis. We defined an a priori dichotomous variable for severe desaturation as a $\geq 20 \%$ decrease in $\mathrm{SpO}_{2}$.

\section{Intubation Guidelines}

Although our NICU does not have a written protocol for intubation procedures, the general guidelines are: the number of attempts is limited to two per intubator; during nonemergent conditions, infants are stabilized with bag mask ventilation between attempts until heart rate and oxygen saturations recover to preprocedural levels, and there is no time limit for intubation attempts.

\section{Statistical Methods}

Statistical analysis was performed using STATA 12.0 (Stata Corp., College Station, Tex., USA). Summary statistics were described with means and standard deviation (SD) for parametric variables and median with interquartile range (IQR) for nonparametric variables. Categorical variables were compared between TI encounters with and without TIAEs using a $\chi^{2}$ test or Fisher's exact test. The Wilcoxon rank-sum test was used for comparison of nonparametric variables.

We developed a logistic regression model for the TIs performed by residents, attendings, and fellows in order to examine the independent association between medical training level and TIAEs. TIs performed by nurse practitioners, physician assistants, staff NICU pediatricians, and nonneonatal physicians were excluded from the model, as experience level for these providers was not recorded in the database. The model included the patient and practice characteristics associated with TIAEs in univariate analysis $(\mathrm{p}<0.1)$ and patient characteristics that were hypothesized a priori to increase the risk of TIAEs: small patient size $(<2 \mathrm{~kg})$ [5] and history of difficult airway [1].

Median severity of oxygen desaturation was summarized for all encounters. Frequency of severe desaturation events was compared between intubator levels using a $\chi^{2}$ test. Initial oxygen saturation level and degree of oxygen desaturation was compared between encounters with and without TIAE using a Wilcoxon ranksum test.

\section{Ethics Board Approval}

The local institutional review board approved this study, and informed consent was waived. 
Fig. 1. TI encounters included in analysis. * Includes laryngeal mask airway (LMA) and fiber optic flexible laryngoscope.

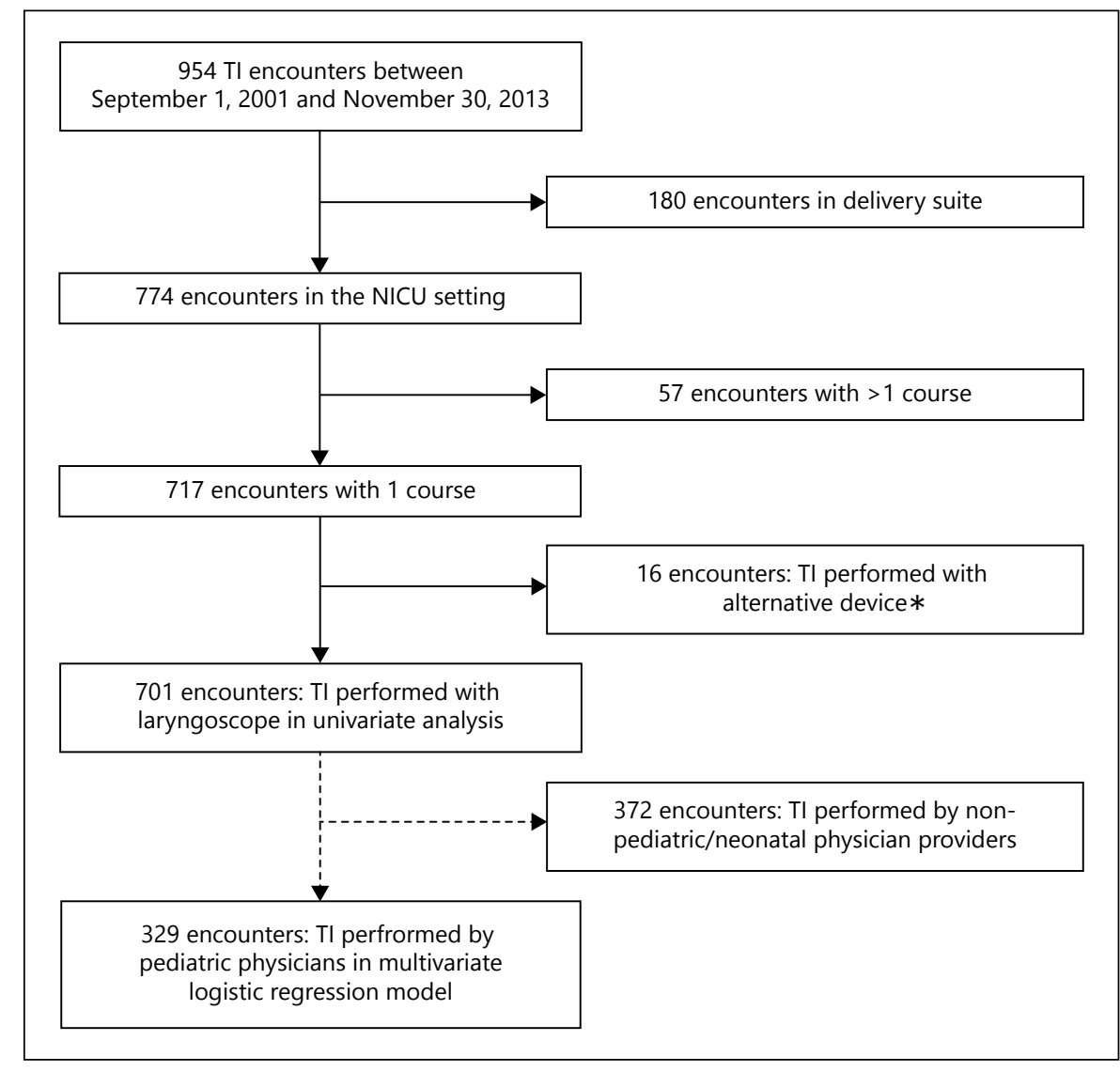

\section{Results}

There were 701 intubation encounters analyzed (fig. 1). The median number of attempts for each was 2 (IQR: 1, 3). At least 1 TIAE was reported in $153(22 \%)$ encounters. Severe TIAEs occurred in $26(3.7 \%)$, and nonsevere TIAEs occurred in 133 (19.0\%). Severe oxygen desaturation ( $\geq 20 \%$ decrease in $\mathrm{SpO}_{2}$ ) occurred in $51.1 \%$ of encounters with available $\mathrm{SpO}_{2}$ data (table 1).

\section{Patient and Practice Factors Associated with TIAEs}

Characteristics such as age, weight, sex, and history of difficult airway did not significantly differ between patients with and without TIAEs (table 2). In univariate analysis, ventilation failure (i.e. rising $\mathrm{CO}_{2}$ ) was the indication for TI more frequently in encounters with TIAEs than without TIAEs ( 38.6 vs. $24.8 \%, \mathrm{p}=0.001$ ). Conversely, endotracheal tube replacement (rather than primary intubation) was less frequently the indication for encounters with TIAEs than without TIAEs ( 15.7 vs. $27.9 \%, \mathrm{p}=0.002$ ).

The most frequently used medications were fentanyl (91.0\%) and morphine (7.0\%). Sedative/narcotic pre- medication use did not significantly differ between encounters with and without TIAEs ( 87.6 vs. $85.6 \%, \mathrm{p}=$ $0.53)$. Paralytic medications were used less frequently in encounters with TIAEs than without TIAEs (65.4 vs. $74.5 \%, \mathrm{p}=0.026)$.

\section{Intubator Characteristics Associated with TIAEs}

Initial intubators were pediatric residents in $15.1 \%$ of encounters (first-attempt success rate $26.4 \%$ ), neonatology fellows in $23.1 \%$ of encounters (first-attempt success rate $50 \%$ ), and neonatology attendings in $8.7 \%$ of encounters (first-attempt success rate $62.3 \%$ ). The remaining intubators were other neonatal clinicians (43.9\%) and physicians from other disciplines $(9.1 \%$; table 3).

TIAEs occurred more frequently during TIs performed by residents (27.4\%) and fellows (22.8\%) compared with attendings (14.8\%; fig. 2). This was not statistically significant in univariate analysis. In the logistic regression model of TIs performed by pediatric/neonatal physicians, the only significant factors associated with decreased risk of TIAEs were attending-level intubator 
Table 1. Incidence of adverse TIAEs during TI encounters

\begin{tabular}{|c|c|}
\hline & $\begin{array}{l}\text { Encounters } \\
\text { with TIAE, } \\
\mathrm{n}(\%)(\mathrm{n}=701)\end{array}$ \\
\hline Severe TIAE & $26(3.7)$ \\
\hline Esophageal intubation - delayed recognition & $14(2)$ \\
\hline Cardiac arrest - patient survived & $6(0.9)$ \\
\hline Airway trauma & $2(0.3)$ \\
\hline Vomit with aspiration & $2(0.3)$ \\
\hline Laryngospasm & $1(0.1)$ \\
\hline Hypotension requiring intervention & $1(0.1)$ \\
\hline Cardiac arrest - patient died & 0 \\
\hline Pneumothorax/pneumomediastinum & 0 \\
\hline Malignant hyperthermia & 0 \\
\hline Nonsevere TIAE ${ }^{\mathrm{a}}$ & $133(19.0)$ \\
\hline Esophageal intubation - immediate & \\
\hline recognition & $104(14.8)$ \\
\hline Mainstem intubation & $14(2)$ \\
\hline Vomit without aspiration & $9(1.3)$ \\
\hline Gum or oral trauma & $9(1.3)$ \\
\hline Lip trauma & $8(1.1)$ \\
\hline Pain or agitation delaying intubation & $5(0.7)$ \\
\hline Dysrhythmia & $4(0.6)$ \\
\hline Medication error & 0 \\
\hline Epistaxis & 0 \\
\hline Hypertension requiring intervention & 0 \\
\hline One or more TIAE (any type) $)^{\mathrm{b}}$ & $153(21.8)$ \\
\hline Severe desaturation $\left(\geq 20 \%\right.$ decrease in $\left.\mathrm{SpO}_{2}\right)$ & $341 / 668(51.1)$ \\
\hline
\end{tabular}

a Nonsevere TIAE: 117 encounters with 1 nonsevere TIAE, 13 encounters with 2 nonsevere TIAEs, 2 encounters with 3 nonsevere TIAEs, 1 encounter with 4 nonsevere TIAEs. ${ }^{b}$ All TIAE: 132 encounters with 1 TIAE, 17 encounters with 2 TIAEs, 3 encounters with 3 TIAEs, 1 encounter with 4 TIAEs.
Table 2. Patient and practice characteristics of TI encounters with and without TIAE

\begin{tabular}{|c|c|c|c|}
\hline Variable & $\begin{array}{l}\text { TIAE } \\
(\mathrm{n}=153)\end{array}$ & $\begin{array}{l}\text { No } \\
\text { TIAE } \\
(\mathrm{n}=548)\end{array}$ & $\mathrm{p}$ value \\
\hline \multicolumn{4}{|l|}{ Patient age, months } \\
\hline $\begin{array}{l}\text { (median, IQR) } \\
\text { Patient weight }\end{array}$ & $1(0,2)$ & $1(0,2)$ & $\begin{array}{l}0.67 \\
0.27\end{array}$ \\
\hline$<1,500 \mathrm{~g}$ & $30(19.6)$ & $81(14.8)$ & \\
\hline $1,500-1,999 \mathrm{~g}$ & $15(9.8)$ & $46(8.4)$ & \\
\hline$\geq 2,000 \mathrm{~g}$ & $108(70.6)$ & $421(76.8)$ & \\
\hline Male sex & $86(56.2)$ & $276(50.4)$ & 0.20 \\
\hline History of difficult airway & $29(19.0)$ & $96(17.5)$ & 0.68 \\
\hline \multicolumn{4}{|l|}{ Indication $^{\mathrm{a}}$} \\
\hline \multicolumn{4}{|l|}{ Elective primary } \\
\hline intubation & $15(9.8)$ & $58(10.6)$ & 0.78 \\
\hline Oxygen failure & $29(19.0)$ & $76(13.9)$ & 0.12 \\
\hline Ventilation failure & $59(38.6)$ & $136(24.8)$ & 0.001 \\
\hline Apnea & $18(11.8)$ & $49(8.9)$ & 0.29 \\
\hline \multicolumn{4}{|l|}{ Upper airway } \\
\hline \multicolumn{4}{|l|}{ Reintubation after } \\
\hline unplanned extubation & $7(4.6)$ & $44(8.0)$ & 0.15 \\
\hline $\begin{array}{l}\text { Replace endotracheal } \\
\text { tube }\end{array}$ & $24(15.7)$ & $153(27.9)$ & 0.002 \\
\hline Nasal intubation & $4(2.6)$ & $25(4.6)$ & $0.36^{\mathrm{b}}$ \\
\hline \multicolumn{4}{|l|}{ Sedative/narcotic } \\
\hline medications & $134(87.6)$ & $469(85.6)$ & 0.53 \\
\hline Paralytic medications & $100(65.4)$ & $408(74.5)$ & 0.026 \\
\hline
\end{tabular}

Unless otherwise indicated, values represent patient $\mathrm{n}(\%)$. Values in bold represent $\mathrm{p}<0.05 .{ }^{\mathrm{a}}$ More than one indication may be present per encounter. Indication not recorded in 34 (4.9\%) encounters. ${ }^{\text {b }}$ Fisher's exact test.

Table 3. Intubator characteristics for TI encounters $(n=701)$

\begin{tabular}{llcccc}
\hline Intubator & $\begin{array}{l}\text { Performed } \\
\text { first } \\
\text { attempt }\end{array}$ & $\begin{array}{l}\text { Performed } \\
\text { second } \\
\text { attempt }\end{array}$ & $\begin{array}{l}\text { Performed } \\
\text { third } \\
\text { attempt }\end{array}$ & $\begin{array}{l}\text { First-attempt } \\
\text { success }\end{array}$ & Overall success $^{\mathrm{a}}$ \\
\hline Resident, general pediatrics & $106(15.1)$ & $41(10.8)$ & $7(3.1)$ & $28 / 106(26.4)$ & $34 / 106(32.1)$ \\
NICU fellow & $162(23.1)$ & $104(27.4)$ & $82(36.4)$ & $81 / 162(50)$ & $113 / 162(69.8)$ \\
NICU attending & $61(8.7)$ & $56(14.7)$ & $64(28.4)$ & $38 / 61(62.3)$ & $53 / 61(86.9)$ \\
NICU nonphysician clinician $^{\mathrm{b}}$ & $308(43.9)$ & $142(37.4)$ & $36(16.0)$ & $132 / 308(42.9)$ & $190 / 308(61.7)$ \\
Non-NICU physician $^{\mathrm{c}}$ & $64(9.1)$ & $37(9.7)$ & $36(16.0)$ & $42 / 64(65.6)$ & $53 / 64(82.8)$ \\
Total $^{\text {Not }}$ & 701 & 380 & 225 & $321 / 701(45.8)$ & $443 / 701(63.2)$ \\
\hline
\end{tabular}

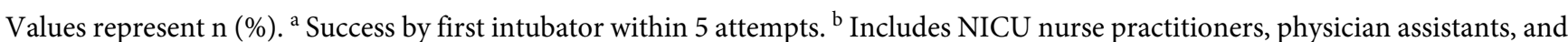
staff pediatricians. ${ }^{\mathrm{c}}$ Includes physicians from otolaryngology, anesthesiology, and general surgery. 
Fig. 2. Proportion of TIs performed by residents/fellows/attendings with severe desaturation $\left(\geq 20 \%\right.$ decrease in $\left.\mathrm{SpO}_{2}\right)$ and any TIAE $(n=329)$. Results are shown for all encounters and separated by intubator training level. Desaturations: $p=0.008, \chi^{2}$ ( 2 d.f.). TIAE: $\mathrm{p}=0.045$, attending (vs. resident) in multivariate logistic regression model including: training level, paralytic medications, small patient size, indication of ventilation failure, replacement of endotracheal tube, and history of difficult airway.

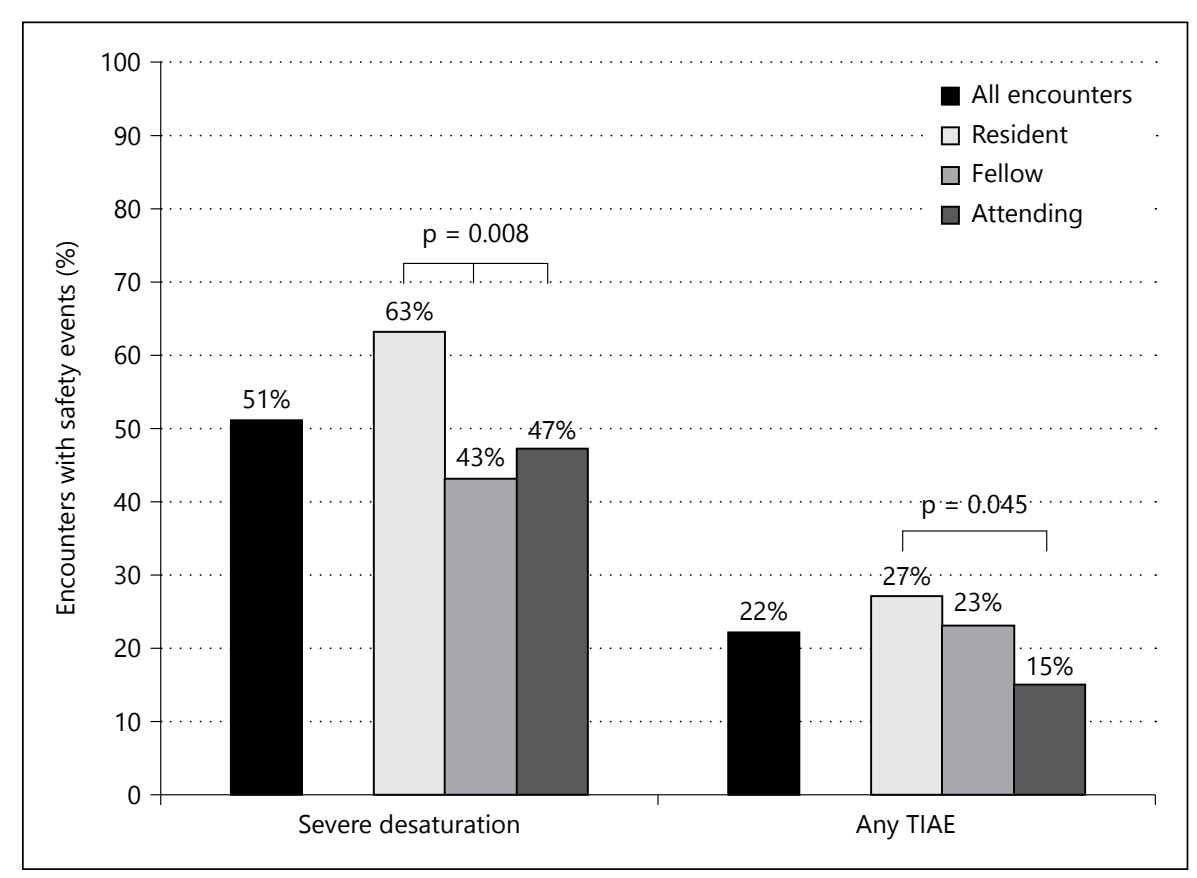

Table 4. Logistic regression of characteristics associated with TIAEs, including encounters with TI performed by residents/fellows/attendings $(\mathrm{n}=329)$

\begin{tabular}{|c|c|c|}
\hline & $\begin{array}{l}\text { TIAE, OR } \\
(95 \% \text { CI })\end{array}$ & $\begin{array}{l}\text { Adjusted } \\
\text { p value }\end{array}$ \\
\hline \multicolumn{3}{|l|}{ First intubator } \\
\hline Resident (reference) & - & - \\
\hline Fellow (compared to resident) & $0.81(0.44,1.48)$ & 0.49 \\
\hline Attending (compared to resident) & $0.40(0.16,0.98)$ & 0.045 \\
\hline History of difficult airway & $1.33(0.66,2.68)$ & 0.42 \\
\hline Paralytic medications & $0.45(0.25,0.81)$ & 0.008 \\
\hline Patient weight $<2 \mathrm{~kg}$ & $1.13(0.60,2.11)$ & 0.71 \\
\hline Change endotracheal tube & $0.66(0.32,1.36)$ & 0.26 \\
\hline Ventilation failure & $1.72(0.93,3.18)$ & 0.08 \\
\hline
\end{tabular}

Logistic Regression Pseudo $\mathrm{R}^{2}=0.053, \mathrm{p}=0.009$, d.f. $=7$. Numbers in bold represent $\mathrm{p}<0.05$.

(odds ratio (OR) $0.40,95 \%$ CI: $0.16,0.98$ compared to residents) and paralytic medication use (OR $0.45,95 \% \mathrm{CI}$ : $0.25,0.81$; table 4$)$.

\section{Oxygen Desaturation}

Pulse oximetry data were available in 668 (95.3\%) encounters. The median preintubation saturation was $100 \%$ (IQR: 98, 100) for all encounters and did not significant- ly differ between encounters with and without TIAEs $(\mathrm{p}=$ 0.22 ). The median decrease in $\mathrm{SpO}_{2}$ was $20 \%$ (IQR: 5,39 ) and was significantly greater when TIAEs occurred (40 vs. $15 \%, \mathrm{p}<0.001)$. Severe oxygen desaturation events $\left(\geq 20 \%\right.$ decrease in $\mathrm{SpO}_{2}$ ) occurred in $51.1 \%$ of encounters. The median preintubation saturation was $100 \%$ for resident, fellow, and attending intubators. Severe desaturation was more likely to occur with resident intubators (62.8\%) compared to fellow (43.2\%) or attending intubators $(47.5 \%), \mathrm{p}=0.008$ (fig. 2 ).

\section{Discussion}

Our prospective cohort study characterized the incidence of TIAEs and severe oxygen desaturation during TI in the NICU. TIAEs occurred in $22 \%$ and severe desaturations occurred in $51 \%$ of all TI encounters. Attending-level intubator (vs. resident) and use of paralytics were independently associated with significantly fewer TIAEs. Severe oxygen desaturations were more frequent in TIs performed by residents. The median decrease in $\mathrm{SpO}_{2}$ was significantly greater in TIs with TIAEs than TIs without TIAEs, suggesting that TIAEs have a meaningful clinical impact.

No previous study has reported on an inclusive list of TIAEs in NICU patients. Our results are similar to a study of TIAEs in 15 PICUs using the NEAR4KIDS airway registry [4]: TIAEs occurred in $21 \%$ of TI encounters in that 
study, and esophageal intubation with immediate recognition was the most commonly reported TIAE. Consistent with our study results in the NICU, those authors also demonstrated an independent association between intubator training level and TIAEs in the PICU.

Small published reports of TI safety in the NICU setting have suggested that deterioration in oxygen saturation and heart rate are common $[3,5,7]$. Venkatesh et al. [3] prospectively collected data on 93 TI encounters performed in 3 NICUs. The median lowest recorded $\mathrm{SpO}_{2}$ was $65 \%$ in those encounters, and $21 \%$ of infants experienced a heart rate of $<60$ beats/min during TI. Using video review of 60 attempted TIs in the delivery room, O'Donnell et al. [7] found that $\geq 10 \%$ deterioration in $\mathrm{SpO}_{2}$ and/or heart rate occurred in $49 \%$ of intubation encounters. Simon et al. [5] performed a combined multisite study of TI in NICUs and PICUs. Oxygen desaturation (absolute $\mathrm{SpO}_{2}<90 \%$ ) and/or bradycardia (heart rate $<100$ beats/min) occurred in $23.6 \%$ of the neonates included in their study; these events were significantly more likely to occur when TI was performed by intubators with $<10$ prior airway experiences. In our study, the $\mathrm{SpO}_{2}$ declined by $\geq 20 \%$ in over half of TI encounters, and severe oxygen desaturations were more frequently observed with resident airway providers. However, bradycardia was only recorded when heart rate was $<60$ beats/min, limiting our ability to compare the incidence of bradycardia with previously published studies.

More frequent TIAEs and more severe oxygen desaturations during TIs performed by residents may be due to lack of proficiency in endotracheal intubation. Previous studies have demonstrated that less experience is associated with increased duration of intubation attempts and decreased TI success rates [7-11]. Pediatric residents in our study were only successful in $26 \%$ of their first TI attempts. Poor resident performance in TI, both in terms of safety and success, may be partly due to the fact that opportunities to perform neonatal intubation have declined. Potential explanations for this trend include changes to the neonatal resuscitation program, which no longer recommends routine intubation and tracheal suctioning of vigorous meconium-stained newborns [12], and increased use of noninvasive respiratory support in preterm infants $[13,14]$. Reductions in residency training work hours further limit the number of procedural opportunities for pediatric residents [15].

One important finding in this study was the association of paralytic medication use with fewer TIAEs. We found that the use of paralytic medications use was significantly less common in encounters with any TIAEs and also in encounters with severe TIAEs, similar to data from critically ill adults [16]. The high prevalence of sedative/narcotic use suggests that there was enough time in the majority of TI encounters to prepare and administer premedications. Although premedication use is recommended for nonemergent neonatal intubation [17], no single premedication regimen has been demonstrated to have clear superiority in improving the safety of neonatal intubation over others. The use and selection of premedications for nonemergent neonatal intubation remain variable in practice [18-20]. Studies of neuromuscular blockade for intubation in neonates have largely focused on outcomes related to physiologic variables or intubation success [21-25]. Our results suggest that paralytic medication use is associated with fewer TIAEs in the NICU, providing data to hypothesize that paralytic use improves the safety of TI in the NICU.

This study has several limitations. TIAEs were identified by self-report from the clinical team; this might have underestimated the true incidence of TIAEs. This single site study was performed in a large referral NICU with complex medical and surgical patients and may not generalize to other NICUs or the delivery room setting. Intubators' years of experience or previous intubation exposures were not recorded in this dataset. We excluded nonphysician clinicians from our logistic model because years of experience/training level ranges widely within this group, but this information was not available in this dataset. Lastly, certain patient characteristics, such as age in days or weeks, gestational age, and numerical heart rate, were not recorded. Development of a multicenter neonatal-specific airway registry is underway to address these limitations.

\section{Conclusions}

Adverse TIAEs (22\%) and severe desaturation events during TI (51\%) are common in the NICU setting. These adverse events occur more frequently in TIs performed by resident physicians, compared with fellow or attending physicians. Potentially modifiable risk factors associated with TIAEs include intubator training level and use of paralytic medications.

\section{Funding}

E.E.F. received funding support from NIH 5T32HD060550-03, V.N. is supported through Endowed Chair, Critical Care Medicine, Children's Hospital of Philadelphia, and A.N. received support from AHRQ R03HS021583.
Foglia/Ades/Napolitano/Leffelman/ Nadkarni/Nishisaki 


\section{References}

1 Nishisaki A, Turner DA, Brown CA, Walls RM, Nadkarni VM; National Emergency Airway Registry for Children (NEAR4KIDS); Pediatric Acute Lung Injury and Sepsis Investigators (PALISI) Network: A National Emergency Airway Registry for children: landscape of tracheal intubation in 15 PICUs. Crit Care Med 2013;41:874-885.

-2 Carroll CL, Spinella PC, Corsi JM, Stoltz P, Zucker AR: Emergent endotracheal intubations in children: be careful if it's late when you intubate. Pediatr Crit Care Med 2010;11: 343-348.

-3 Venkatesh V, Ponnusamy V, Anandaraj J, Chaudhary R, Malviya M, Clarke P, Arasu A, Curley A: Endotracheal intubation in a neonatal population remains associated with a high risk of adverse events. Eur J Pediatr 2011; 170:223-227.

-4 Sanders RC, Giuliano JS, Sullivan JE, Brown CA, Walls RM, Nadkarni V, Nishisaki A; National Emergency Airway Registry for Children Investigators and Pediatric Acute Lung Injury and Sepsis Investigators Network: Level of trainee and tracheal intubation outcomes. Pediatrics 2013;131:e821-e828.

-5 Simon L, Trifa M, Mokhtari M, Hamza J, Treluyer JM: Premedication for tracheal intubation: a prospective survey in 75 neonatal and pediatric intensive care units. Crit Care Med 2004;32:565-568.

-6 Nishisaki A, Ferry S, Colborn S, DeFalco C, Dominguez T, Brown CA, Helfaer MA, Berg RA, Walls RM, Nadkarni VM; National Emergency Airway Registry (NEAR); National Emergency Airway Registry for Kids (NEAR4KIDS) Investigators: Characterization of tracheal intubation process of care and safety outcomes in a tertiary pediatric intensive care unit. Pediatr Crit Care Med 2012; 13:e5-e10.

-7 O’Donnell CP, Kamlin CO, Davis PG, Morley CJ: Endotracheal intubation attempts during neonatal resuscitation: success rates, duration, and adverse effects. Pediatrics 2006; 117:e16-e21.

$>8$ Leone TA, Rich W, Finer NN: Neonatal intubation: success of pediatric trainees. J Pediatr 2005;146:638-641.
\9 Haubner LY, Barry JS, Johnston LC, Soghier L, Tatum PM, Kessler D, Downes K, Auerbach M: Neonatal intubation performance: room for improvement in tertiary neonatal intensive care units. Resuscitation 2013;84: 1359-1364.

10 Falck AJ, Escobedo MB, Baillargeon JG, Villard LG, Gunkel JH: Proficiency of pediatric residents in performing neonatal endotracheal intubation. Pediatrics 2003;112:12421247.

-11 Bismilla Z, Finan E, McNamara PJ, LeBlanc $\mathrm{V}$, Jefferies A, Whyte H: Failure of pediatric and neonatal trainees to meet Canadian Neonatal Resuscitation Program standards for neonatal intubation. J Perinatol 2010;30:182187.

12 Kattwinkel J, Perlman JM, Aziz K, Colby C, Fairchild K, Gallagher J, Hazinski MF, Halamek LP, Kumar P, Little G, McGowan JE, Nightengale B, Ramirez MM, Ringer S, Simon WM, Weiner GM, Wyckoff M, Zaichkin J: Neonatal resuscitation: 2010 American Heart Association Guidelines for Cardiopulmonary Resuscitation and Emergency Cardiovascular Care. Pediatrics 2010;126:e1400e1413.

13 Committee on Fetus and Newborn; American Academy of Pediatrics: Respiratory support in preterm infants at birth. Pediatrics 2014; 133:171-174.

14 Sweet DG, Carnielli V, Greisen G, Hallman M, Ozek E, Plavka R, Saugstad OD, Simeoni U, Speer CP, Vento M, Halliday HL: European consensus guidelines on the management of neonatal respiratory distress syndrome in preterm infants - 2013 update. Neonatology 2013;103:353-368.

15 Gozzo YF, Cummings CL, Chapman RL, Bizzarro MJ, Mercurio MR: Who is performing medical procedures in the neonatal intensive care unit? J Perinatol 2011;31:206-211.

16 Wilcox SR, Bittner EA, Elmer J, Seigel TA, Nguyen NTP, Dhillon A, Eikermann M, Schmidt U: Neuromuscular blocking agent administration for emergent tracheal intubation is associated with decreased prevalence of procedure-related complications. Crit Care Med 2012;40:1808-1813.
17 Kumar P, Denson SE, Mancuso TJ; Committee on Fetus and Newborn, Section on Anesthesiology and Pain Medicine: Premedication for nonemergency endotracheal intubation in the neonate. Pediatrics 2010;125: 608-615.

18 Durrmeyer X, Daoud P, Decobert F, Boileau $P$, Renolleau S, Zana-Taieb E, Saizou C, Lapillonne A, Granier M, Durand P, Lenclen R, Coursol A, Nicloux M, de Saint Blanquat L, Shankland R, Boëlle PY, Carbajal R: Premedication for neonatal endotracheal intubation: results from the epidemiology of procedural pain in neonates study. Pediatr Crit Care Med 2013;14:e169-e175.

19 Wheeler B, Broadbent R, Reith D: Premedication for neonatal intubation in Australia and New Zealand: a survey of current practice. J Paediatr Child Health 2012;48:997-1000.

20 Chaudhary R, Chonat S, Gowda H, Clarke P, Curley A: Use of premedication for intubation in tertiary neonatal units in the United Kingdom. Paediatr Anaesth 2009;19:653658.

21 Kelly MA, Finer NN: Nasotracheal intubation in the neonate: physiologic responses and effects of atropine and pancuronium. J Pediatr 1984;105:303-309.

22 Barrington KJ, Finer NN, Etches PC: Succinylcholine and atropine for premedication of the newborn infant before nasotracheal intubation: a randomized, controlled trial. Crit Care Med 1989;17:1293-1296.

23 Norman E, Wikström S, Hellström-Westas L, Turpeinen U, Hämäläinen E, Fellman V: Rapid sequence induction is superior to morphine for intubation of preterm infants: a randomized controlled trial. J Pediatr 2011;159: 893-899.e1.

24 Le CN, Garey DM, Leone TA, Goodmar JK, Rich W, Finer NN: Impact of premedication on neonatal intubations by pediatric and neonatal trainees. J Perinatol 2014;34:458-460.

25 Roberts KD, Leone TA, Edwards WH, Rich WD, Finer NN: Premedication for nonemergent neonatal intubations: a randomized, controlled trial comparing atropine and fentanyl to atropine, fentanyl, and mivacurium. Pediatrics 2006;118:1583-1591. 